\title{
Therapeutic approaches to slowing the progression of diabetic nephropathy - is less best?
}

\author{
Eva Vivian, ${ }^{1}$ Chelsea Mannebach ${ }^{2}$ \\ 'University of Wisconsin-Madison, School of Pharmacy, Madison, USA; ldaho State University Affiliate Faculty, Boise Veterans Affairs Medical Center, Boise, USA
}

\begin{abstract}
Objective: Angiotensin II receptor blockers (ARBs) and angiotensin-converting enzyme (ACE) inhibitors are known to reduce proteinuria and have been the first-line agents in the management of diabetic nephropathy for the past 20 years. This review covers recent studies that compare the benefit of additional blockage of the renin-angiotensinaldosterone system through combination therapy with an ACE inhibitor and ARB, or a direct renin inhibitor (DRI), to monotherapy.

Design: Primary and review articles that addressed the pathophysiology, diagnosis, and therapeutic options for attenuating the progression of diabetic nephropathy were retrieved through a MEDLINE search (January 1990 to December 2012) and the bibliographies of identified articles were reviewed. English language sources were searched using the following search terms: diabetes mellitus, nephropathy, proteinuria, ACE inhibitors, ARBs, and DRIs.

Setting: Randomized, placebo-controlled, short- and long-term studies published in peer-reviewed journals that were determined to be methodologically sound, with appropriate statistical analysis of the results, were selected for inclusion in this review.

Participants: Adult ( $\geq 18$ years) patients with diabetic nephropathy.

Measurements: Serum creatinine level was used to estimate glomerular filtration rate (GFR). GFR was calculated using the four-variable Modification of Diet in Renal Disease formula. The urine albumin-to-creatinine ratio was measured at baseline and at the conclusion of each study. A value between $3.4 \mathrm{mg} / \mathrm{mmol}$ and below $33.9 \mathrm{mg} / \mathrm{mmol}$ was defined as microalbuminuria. A value of $33.9 \mathrm{mg} / \mathrm{mmol}$ or more (approximately $300 \mathrm{mg} / \mathrm{g}$ creatinine) was defined as macroalbuminuria.
\end{abstract}

Results: ACE inhibitors and ARBs are now the mainstay of treatment for diabetic nephropathy. However, combination therapy with an ACE inhibitor and an ARB, or DRI, has not been found to be more effective than monotherapy with an ACE inhibitor or ARB, and may increase the risk of hyperkalemia or acute kidney injury.

Conclusion: Both ACE inhibitors and ARBs remain the first-line agents in attenuating the progression of diabetic nephropathy; however, recent studies suggest that combining an ACE inhibitor with an ARB, or combining a DRI with an ACE inhibitor or ARB, may increase adverse events without clinical benefits to offset them.

Keywords: angiotensin-converting enzyme inhibitors, calcium channel blockers, angiotensin II receptor blockers, diabetic nephropathy, microvascular complications, diabetes mellitus, direct renin inhibitors, combination therapy

Citation

Provenance

Dates

Copyright

Correspondence address

Email address

Competing interests

Abbreviations
Vivian E, Mannebach C. Therapeutic approaches to slowing the progression of diabetic nephropathy - is less best? Drugs in Context 2013; 212249. doi: $10.7573 /$ dic. 212249

Invited; externally peer reviewed

Submitted: 18 January 2013; Accepted, subject to peer review: 28 January 2013; Published: 27 March 2013

(C) 2013 Vivian E, Mannebach C. This is an open-access article distributed under the terms of the Creative Commons Attribution License (CC-BY-NC-ND 3.0) which allows unrestricted sharing, copying and distribution for personal use provided it is properly attributed. Commercial use is not permitted.

Eva M Vivian, PharmD, CDE, BC-ADM, FAADE, Clinical Associate Professor, University of Wisconsin-Madison, School of Pharmacy, 777 Highland Avenue, Madison, WI 53705, USA

emvivian@pharmacy.wisc.edu

Eva Vivian and Chelsea Mannebach have declared that there are no competing interests.

AACE, American Association of Clinical Endocrinologists; ACE, angiotensin converting enzyme; ADA, American Diabetes Association; $A R B$, angiotensin II receptor blocker; $C C B$, calcium channel blocker; $\mathrm{Cl}$, confidence interval; $C K D$, chronic kidney disease; DN, diabetic nephropathy; DRI, direct renin inhibitor; ESRD, end-stage renal disease; GFR, glomerular filtration rate; HDL, high-density lipoprotein; HR, hazard ratio; IDDM, insulin-dependent diabetes mellitus; IDF, International Diabetes Federation; LDL, low-density lipoprotein; NIDDM, non-insulin dependent diabetes mellitus; RAS, renin-angiotensin system; SBP, systolic blood pressure; $\mathrm{SrCr}$, serum creatinine; $\mathrm{UACR}$, urinary albumin-to-creatinine ratio; $\mathrm{UAE}$, urine albumin excretion; UAER, urinary albumin excretion rate; VLDL, very-low-density lipoprotein

\section{Introduction}

Diabetes mellitus and hypertension are the leading causes of end-stage renal disease (ESRD), accounting for approximately $40 \%$ and $25 \%$ of all cases, respectively $[1,2]$. Between $20 \%$ and

Drugs in Context - The journal of interventions in clinical practice This full text PDF downloaded from www.drugsincontext.com Drugs in Context 2013; 212249. ISSN 1740-4398

Copyright (C) 2013 Vivian E, Mannebach C. Distributed under the terms of the Creative Commons Attribution License CC-BY-NC-ND 3.0.

No other uses without permission.
$30 \%$ of patients with type 1 or type 2 diabetes develop evidence of nephropathy. Patients with type 2 diabetes account for more than half the patients with diabetes who develop end stage renal disease because of the greater prevalence of type 2 diabetes [3]. Factors important in the pathogenesis of diabetic nephropathy (DN) include hyperglycemia, hypertension, lipid abnormalities, albuminuria or proteinuria, ethnicity, genetic predisposition, cigarette smoking, and increasing age $[1,3]$.

The clinical course of DN includes an initial increase in glomerular filtration rate (GFR), thickening of the glo- 
merular basement membrane, expansion of the mesangium, microalbuminuria, proteinuria, and eventually a decline in glomerular filtration [4]. As renal function declines, arterial blood pressure increases. Systemic hypertension further contributes to the rate of progression to nephropathy and eventually the syndrome can progress to ESRD [5,6]. Since diabetes mellitus, hypertension, and nephropathy all increase the morbidity and mortality associated with cardiovascular disease, interventions that result in blood glucose and blood pressure reduction will reduce the progression of nephropathy and cardiovascular complications $[7,8]$.

Approximately two-thirds of all patients with diabetes have hypertension [9]. Blood pressure control, regardless of the antihypertensive agent chosen, can slow the progression of DN [7]. However, clinical studies have shown that angiotensinconverting enzyme (ACE) inhibitors and angiotensin II receptor blockers (ARBs) have slowed the progression of renal disease via mechanisms that cannot be fully accounted for by blood pressure control alone [10]. Treatment with either drug has become the mainstay of therapy for DN for the past 20 years, along with optimization of glycemic and blood pressure control. However, there is interindividual variability in response to these agents, which can be attributed in part to incomplete angiotensin II receptor blockage [4]. Combinations of an ACE inhibitor plus an $\mathrm{ARB}$, or a direct renin inhibitor (DRI), provide additional lowering of albuminuria, but are associated with a higher frequency of adverse events [11]. Diuretics, calcium channel blockers (CCBs), and beta blockers should be used as additional therapy to lower blood pressure in patients already treated with ACE inhibitors or ARBs, or as an alternative for patients who cannot tolerate ACE inhibitors or ARBs [10].

The objective of this paper is to review recent trials that assessed the effectiveness of combination therapy with ACE inhibitors, ARBs, and other RAS (renin-angiotensin system)-blocking agents. This paper also discusses the outcomes of these studies and the recommended therapeutic options available for attenuating the progression of nephropathy.

\section{Pathophysiology of diabetic nephropathy}

Several metabolic and hemodynamic processes contribute to the development of DN. Hyperglycemia may lead to nephropathy by a number of mechanisms, including hypertrophy and thickening of the basement membrane, increased endothelial cell permeability to albumin, and increased matrix protein synthesis $[3,4]$. Hyperglycemia may also cause an increase in vasodilatory prostaglandins, which in turn causes an increase in both renal perfusion and intraglomerular pressure, and ultimately results in hyperfiltration $[3,4,8]$. Sustained hyperglycemia is also associated with the formation of advanced glycated end products. The accumulation of these end products in the kidney leads to cytokine production and subsequently to mesangial hyperplasia $[4,8]$. In addition, excess glucose is converted to sorbitol by aldose reductase in the kidney through the polyol pathway [8]. An increase in intracellular sorbitol results in the depletion of intracellular myoinositol leading to afferent arteriolar vasodilatation, increased renal blood flow, and increased glomerular capillary pressure. The polyol pathway also causes an increase in oxidative stress and kidney damage. Lastly, hyperglycemia increases the activity of protein kinase $\mathrm{C}$ in vascular smooth muscle and endothelial cells, which may also contribute to DN $[4,8]$.

Systemic hypertension contributes to the development of DN via associated glomerular hypertension [4,5,7]. Hemodynamic factors alter the function of glomerular, mesangial, and epithelial cells which results in an increase in mesangial matrix formation and basement membrane thickening. Vasoregulatory peptides such as endothelial-derived relaxing factor, tissue plasminogen activator, endothelin-1, and platelet-derived growth factor $\mathrm{B}$ are also affected by intraglomerular hemodynamic factors. An increase in systemic blood pressure ultimately leads to extracellular matrix accumulation, increased glomerular permeability, proteinuria, and glomerular sclerosis.

There may also be a genetic link to the development of DN [12]. One theory is that a polymorphism of the $A C E$ gene may lead to lower serum ACE levels [13]. As a result, affected patients would have increased angiotensin II activity and resistance to inhibition of ACE. Although this theory seems plausible, current data on this polymorphism are inconclusive. A disproportionate distribution among different races also suggests genetic predisposition. DN is more common in nonWhite populations, specifically African-Americans, Native Americans, Mexican-Americans, Asian-Americans, and those of Pacific Island descent [14].

Other factors associated with DN include cigarette smoking and elevated total cholesterol levels $[15,16]$. Progression to nephropathy tends to be more rapid in smokers compared to nonsmokers [15]. Patients with diabetes and microalbuminuria have been found to have lipid abnormalities including increased low-density lipoprotein (LDL) cholesterol levels, increased lipoprotein(a) levels, and decreased high-density lipoprotein (HDL) cholesterol levels [16]. In patients with type 1 diabetes mellitus, total and LDL cholesterol levels have been found to be independent risk factors for the progression of renal disease [16].

In patients with diabetes, microalbuminuria is often an early indicator of nephropathy as well as a marker for increased risk in cardiovascular morbidity and mortality [3]. Approximately $80 \%$ of patients with type 1 diabetes mellitus will experience an increase in albumin excretion at a rate of $10-20 \%$ per year if left untreated [3]. Once albuminuria occurs, glomerular filtration falls at a rate of $2-20 \mathrm{~mL} / \mathrm{min}$ per year [17-20]. Within 10 years, approximately half of the patients with type 1 diabetes who developed albuminuria will progress to $\operatorname{ESRD}[3,4]$. For this reason, it is important to achieve near normoglycemia to delay the onset and progression of increased urine albumin excretion (UAE) [3,10,19,20-22]. The American Diabetes Association (ADA), American Association of Clinical Endocrinologists (AACE), and International Diabetes Federation (IDF) strongly recommend either an ACE inhibitor or an ARB for patients with moderately elevated (30-299 mg/day) or high levels ( $\geq 300 \mathrm{mg} /$ day) of UAE $[10,21,22]$. ARBs do not prevent the onset of albuminuria in normotensive patients with type 1 or type 2 diabetes, but have been shown to attenuate the progression from microalbuminuria to macroalbuminuria in patients with type 2 
diabetes [11]. ACE inhibitors and ARBs are not recommended for the primary prevention of diabetic kidney disease in normotensive normoalbuminuric patients with diabetes $[10,19]$.

\section{Therapeutic management of diabetic nephropathy}

\section{Protein intake}

Some clinicians believe a protein-restricted diet may help delay the decline in renal function. A protein intake of $0.8-1.0 \mathrm{~g} / \mathrm{kg} /$ day in patients with macroalbuminuria (UAE $>300 \mathrm{mg}$ creatinine $/ 24$ hours), and $0.8 \mathrm{~g} / \mathrm{kg} /$ day in the later stages of chronic kidney disease (CKD) may improve urine albumin excretion rate (UAER) [10]. Despite these recommendations, a Cochrane Systematic Review concluded that studies have not yet clearly demonstrated the benefits of a protein-restricted diet [23]. Further long-term studies are warranted to determine the effects of such a diet on proteinuria, but such a diet may prove useful in reducing urinary protein excretion in patients with worsening nephropathy despite well-controlled blood pressure and blood glucose levels and optimal doses of ACE inhibitor or ARB therapy [10].

\section{Glycemic control}

Strict glycemic control has been shown to delay the progression of diabetes-related microvascular complications. The Diabetes Control and Complications Trial Research Group [24] and UK Prospective Diabetes Study Group [25] reported that tight glycemic control can delay the progression of microvascular complications. The ADA guidelines recommend a glycosylated hemoglobin level of less than $7 \%$ in patients with diabetes mellitus; however, more or less stringent glycemic goals may be suitable for individual patients [10].

\section{Cholesterol control}

Patients with diabetes mellitus are at high risk for cardiovascular disease $[26,27]$. Aggressive treatment of dyslipidemia is necessary to decrease the risk of macrovascular and microvascular complications. Patients with diabetes mellitus tend to have a unique type of dyslipidemia that consists of elevated LDL and triglyceride levels, reduced HDL levels, and increased platelet adhesiveness, all of which can contribute to the development of arteriolar sclerosis [28]. Arteriolar sclerosis can then result in increased susceptibility to pyelonephritis, papillary necrosis, and tubular lesions of the kidney.

There is also evidence to suggest a relationship between albuminuria and the rate of LDL production [28]. Following glomerular injury and hypoalbuminuria, the liver produces excessive amounts of very-low-density lipoprotein (VLDL). Oxidization of excessive LDL may result in mesangial cell expansion, increased basement membrane permeability, and glomerular damage. Aggressive treatment of dyslipidemia will reduce the risk of cardiovascular disease in patients with diabetes mellitus. Primary therapy should focus on obtaining LDL levels of less than $100 \mathrm{mg} / \mathrm{dL}$, triglyceride levels less than $150 \mathrm{mg} / \mathrm{dL}$, and HDL levels greater than $40 \mathrm{mg} / \mathrm{dL}$ for men and greater than $50 \mathrm{mg} / \mathrm{dL}$ for women [10]. The National Kidney Foundation currently recommends using LDL cholesterol-lowering medicines, such as statins or a statin/ezetimibe combination, to reduce the risk of major atherosclerotic events in patients with diabetes and CKD [19].

\section{Blood pressure control}

Both systolic and diastolic hypertension accelerate the progression of nephropathy; therefore, aggressive treatment of hypertension may slow the progression of nephropathy. The UK Prospective Diabetes Study Group [29] reported that tight blood pressure control, defined as a blood pressure of less than 150/85 $\mathrm{mmHg}$, reduced the risk of death and complications related to diabetes mellitus. Large prospective randomized studies in patients with type 1 diabetes have demonstrated that maintaining a lower systolic blood pressure (SBP) $(<140 \mathrm{mmHg})$ using ACE inhibitors provides an added benefit over other antihypertensive agents in delaying the progression of DN [30]. The use of ACE inhibitors and ARBs has been found to delay the onset of microalbuminuria in type 2 diabetes with hypertension [30,31]. Patients with diabetes and hypertension should be treated to a blood pressure goal of less than $140 / 80 \mathrm{mmHg}$ [10].

\section{Angiotensin-converting enzyme inhibitors and angiotensin receptor blockers}

ACE inhibitors are the oldest class of agents used for the treatment of DN. Inhibition of ACE has been shown to decrease systemic blood pressure, albuminuria, and glomerular capillary pressure [32-42]. ACE inhibitors exert their effect by inhibiting ACE and blocking the breakdown of vasodilating substances such as bradykinin, and thus normalize glomerular capillary pressure and reduce microalbuminuria (Figure 1). With early diagnosis and treatment, ACE inhibitors can delay the progression of nephropathy in patients with microalbuminuria $[10,19,20]$. ADA, AACE, and IDF endorse ACE inhibitors in patients with type 1 diabetes, hypertension, and any degree of albuminuria, and also in patients with type 2 diabetes, hypertension, and microalbuminuria $[10,21,22]$. Numerous studies have established the efficacy of ACE inhibitors in attenuating the progression of nephropathy (Table 1, Section A) [32-42].

Like ACE inhibitors, ARBs reduce blood pressure by decreasing systemic vasoconstriction, reducing aldosterone secretion, and causing vasodilatation of the efferent arterioles of the glomerulus. These drugs inhibit angiotensin II by directly blocking the angiotensin II receptor, thereby decreasing the negative effects of angiotensin II on renal hemodynamics (Figure 1). Unlike the ACE inhibitors, ARBs do not inhibit the breakdown of vasodilating substances such as bradykinin, which is believed to be the reason for lower incidences of dry cough [43]. Angiotensin receptor blockers may play a role in attenuating the progression of DN by reducing systemic blood pressure and slowing UAE. Several trials have shown ARBs to be efficacious in reducing the progression of DN (Table 1, Section B) [44-51]. ADA, AACE, and IDF recommend ARBs as initial agents of choice for patients with type 2 diabetes, hypertension, and macroalbuminuria as they have been shown to prevent nephropathy in this population $[10,21,22]$. 
Figure 1. Renin-angiotensin-aldosterone system diagram.

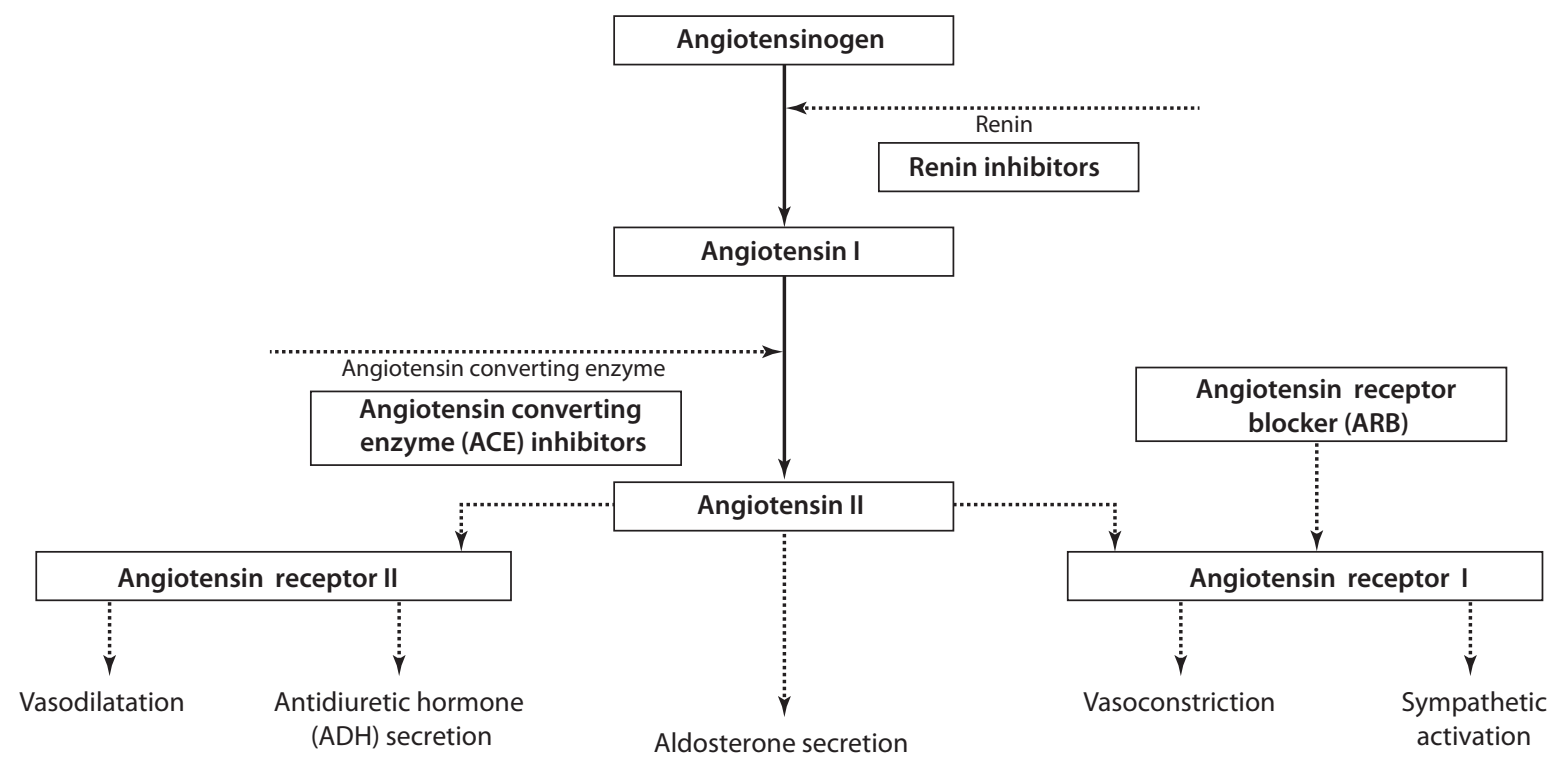

doi: 10.7573/dic.212249.f002

Inhibition of the RAS by ACE inhibitors or ARBs preserves renal function better than other antihypertensive agents, specifically in people with proteinuria above $1 \mathrm{~g}$ per day [3,21]. The greater the proteinuria at baseline (or during follow-up), the larger the effect of ACE inhibitors compared with other antihypertensive drugs in reducing ESRD [3,21]. ACE inhibitors and $\mathrm{ARBs}$ are not recommended for the primary prevention of diabetic kidney disease in normotensive normoalbuminuric patients with diabetes $[10,19]$.

\section{Direct renin inhibitors}

DRIs, namely aliskiren (Tekturna ${ }^{\circledR}$, Novartis Pharmaceuticals Corporation, USA), inhibit plasma renin activity and thus block the conversion of angiotensinogen to angiotensin I (Figure 1). The decrease in angiotensin I inhibits the formation of the blood pressure-elevating peptide, angiotensin II. However, angiotensin II also acts in a negative inhibitory feedback loop that suppresses the release of renin. When an ACE inhibitor or ARB suppresses angiotensin II, this feedback loop is inhibited and can result in a compensatory increase in plasma renin concentration and thus blood pressure elevation. This problem is avoided with DRI therapy because DRIs inhibit renin directly (Table 1, Section C) $[52,53,55]$.

A short-term double-blinded, randomized, crossover study compared aliskiren, $300 \mathrm{mg}$ once daily, irbesartan, $300 \mathrm{mg}$ once daily, and the combination using identical doses, with placebo in 26 patients with type 2 diabetes, hypertension, and albuminuria. Aliskiren treatment reduced albuminuria by $48 \%$ (95\% CI: 27-62) compared with placebo $(p<0.001)$, and irbesartan treatment reduced albuminuria by 58\% (95\% confidence interval (CI): 42-79) compared with placebo $(p<0.001)$. Combination treatment resulted in a $71 \%(95 \%$ CI: 59-79) reduction in albu- minuria which was greater than monotherapy with either agent ( $p<0.001$ and $p=0.028$, respectively) [54]. DRIs are currently not recommended for the treatment of DN $[10,21,22]$.

\section{Combination therapy}

\section{ACE inhibitors and ARBs}

Several studies have assessed the efficacy of RAS dual blockade in reducing proteinuria and delaying the progression of DN (Table 1, Section D) [45,56-64]. Some studies have demonstrated no significant differences in the reduction of proteinuria when comparing combination therapy with ACE inhibitor or ARB monotherapy [56-58]. One proposed explanation for this finding was attributed to the pharmacologic inability of the ARBs to prevent the breakdown of bradykinin, an agent responsible for glomerular efferent vasodilatation and reduction in glomerular filtration rate [56-58]. Conversely, other studies have shown significant reductions in UAE with combination therapy [45,59-65].

The publication of the ONgoing Telmisartan Alone and in combination with Ramipril Global Endpoint Trial (ONTARGET) [65] highlighted the danger of dual inhibition of the RAS, reporting an increased risk of acute dialysis and hyperkalemia in patients prescribed ACE inhibitors and ARBs together. ONTARGET enrolled a total of 25,620 participants aged 55 years or older with atherosclerotic vascular disease or diabetes with end-organ damage. After a 3-week run-in period, the patients were randomized to ramipril, $10 \mathrm{mg}$ per day $(\mathrm{n}=8576)$, telmisartan, $80 \mathrm{mg}$ per day $(n=8542)$, or a combination of both drugs $(n=8502)$. The frequency of the composite primary outcome of the first occurrence of dialysis, doubling of serum creatinine or death, was similar with telmisartan $(\mathrm{n}=1147,13.4 \%)$ and ramipril monotherapy 
Table 1. Clinical trials using ACE inhibitors, ARBs, DRIs, and combination therapy to reduce the progression of DN.

\begin{tabular}{|c|c|}
\hline & giotensin Converting Enzyme Inhibitors - Sec \\
\hline Source & Study Population/Design \\
\hline Mathiesen et al., BMJ, 1991 & \multirow{2}{*}{$\begin{array}{l}\text { Insulin-dependent, diabetic patients with } \\
\text { microalbuminuria ( } n=44) ; 2 \text { groups: captopril, } \\
25 \text { mg daily, placebo daily }\end{array}$} \\
\hline $\begin{array}{l}\text { Efficacy of captopril in postponing nephropathy } \\
\text { in normotensive insulin dependent diabetic } \\
\text { patients with microalbuminuria [32] }\end{array}$ & \\
\hline Ahmad et al., Diabetes Care, 1997 & \multirow{2}{*}{$\begin{array}{l}\text { Normotensive patients with type } 2 \text { diabetes } \\
\text { ( } n=103) ; 2 \text { groups: enalapril, } 10 \text { mg daily, placebo } \\
\text { daily }\end{array}$} \\
\hline $\begin{array}{l}\text { Effective postponement of diabetic nephropathy } \\
\text { with enalapril in normotensive type } 2 \text { diabetic } \\
\text { patients with microalbuminuria [33] }\end{array}$ & \\
\hline Lewis et al., N Engl J Med, 1993 & \multirow{2}{*}{$\begin{array}{l}\text { Patients with insulin-dependent diabetes mellitus } \\
\text { (IDDM), urinary protein excretion }>500 \mathrm{mg} / \text { day } \\
\text { and serum creatinine }(\mathrm{SrCr})<2.5 \mathrm{mg} / \mathrm{dL} \text { ( } \mathrm{n}=409) \text {; } \\
2 \text { groups: captopril, } 25 \mathrm{mg} \text { three times daily, } \\
\text { placebo three times daily }\end{array}$} \\
\hline $\begin{array}{l}\text { The effect of angiotensin-converting-enzyme } \\
\text { inhibition on diabetic nephropathy [34] }\end{array}$ & \\
\hline Ravid et al., Ann Intern Med, 1993 & \multirow{2}{*}{$\begin{array}{l}\text { Patients with type } 2 \text { diabetes mellitus and } \\
\text { microalbuminuria ( } n=94) ; 2 \text { groups: enalapril, } \\
10 \text { mg daily, placebo daily }\end{array}$} \\
\hline $\begin{array}{l}\text { Long-term stabilizing effect of angiotensin- } \\
\text { converting enzyme inhibition on plasma } \\
\text { creatinine and on proteinuria in normotensive } \\
\text { type II diabetic patients [35] }\end{array}$ & \\
\hline Ravid et al., Ann Intern Med, 1998 & \multirow{2}{*}{$\begin{array}{l}\text { Patients with type } 2 \text { diabetes diagnosed after } \\
40 \text { years of age, baseline mean blood pressure } \\
\text { (BP) of }<107 \mathrm{mmHg} \text {, and albuminuria ( } \mathrm{n}=156) ; 2 \\
\text { groups: enalapril, } 10 \mathrm{mg} / \text { day, placebo daily }\end{array}$} \\
\hline $\begin{array}{l}\text { Use of enalapril to attenuate decline in renal } \\
\text { function in normotensive, normoalbuminuric, } \\
\text { patients with type } 2 \text { diabetes mellitus [36] }\end{array}$ & \\
\hline
\end{tabular}

The EUCLID study group, Lancet, 1997

Randomized placebo-controlled trial of lisinopril in normotensive patients with insulindependent diabetes and normoalbuminuria or microalbuminuria [37]

\section{Viberti et al., JAMA, 1994}

Effect of captopril on progression to clinical proteinuria in patients with insulin-dependent diabetes mellitus and microalbuminuria [38]

\section{Sano et al., Diabetes Care, 1994}

Effects of long-term enalapril treatment on persistent microalbuminuria in well-controlled hypertensive and normotensive NIDDM patients [39]

Patients with IDDM, ages 20-59, with

normoalbuminuria or microalbuminuria $(n=530)$; 2 groups: lisinopril, $10 \mathrm{mg}$ daily, placebo daily

Patients with IDDM, persistent microalbuminuria and no hypertension ( $n=92) ; 2$ groups: captopril, $50 \mathrm{mg}$ twice daily, placebo twice daily

Patients with non-insulin dependent diabetes mellitus (NIDDM), persistent microalbuminuria between 20 and $300 \mathrm{mg} / 24$ hours, $\mathrm{SrCr}<1.2 \mathrm{mg} /$ $\mathrm{dL}$, supine $\mathrm{BP}<150 / 90 \mathrm{mmHg}$, and hemoglobin A1c $<10 \%(n=52) ; 4$ groups: patients with normotension who received enalapril, $5 \mathrm{mg}$ daily (NE group), patients with normotension who received placebo daily (NC), patients wellcontrolled with nifedipine, $30 \mathrm{mg}$ daily, plus enalapril, $5 \mathrm{mg}$ daily $(\mathrm{HE})$, patients well-controlled with nifedipine, $30 \mathrm{mg}$ daily plus placebo daily (HC)

Lebovitz et al., Kidney Int Suppl, 1994 Renal protective effects of enalapril in hypertensive NIDDM: role of baseline albuminuria [40]
Patients with NIDDM and hypertension ( $n=121)$; 2 groups: enalapril, $5 \mathrm{mg}$ daily, targeting a diastolic BP of 65 to $80 \mathrm{mmHg}$ ( $\max 40 \mathrm{mg} /$ day), placebo daily
In patients treated with enalapril, albuminuria decreased by a greater extent over the first year and after 5 years when compared to placebo (difference in rate of change in proteinuria $p<0.05$ ).

UAE increased to a much greater extent in the placebo group compared to the enalapril group ( $p=0.001)$ after 6 years of follow-up; the enalapril group had an absolute risk reduction of $12.5 \%$ $(p=0.042)$ for development of microalbuminuria.

UAE was lower in the lisinopril group compared with the placebo group ( $p=0.03$ ) on an intentionto-treat analysis after the 2-year study duration; lisinopril decreased the incidence of renal disease in patients with normoalbuminuria $(p=0.10)$, significantly in those with microalbuminuria $(p=0.04)$.

More patients in the placebo group progressed to proteinuria compared to the captopril group $(p=0.05)$ during the 2 -year study; UAE increased in the placebo group and decreased in the captopril group $(p<0.01)$.

UAE decreased in the NE group compared with the NC group $(p<0.005)$ during the 48-month study period; UAE decreased significantly in the HE group compared to the HC group $(p<0.05)$; no changes in $\mathrm{CrCl}$ (creatine clearance) or BP were observed during the study.

After 3 years, only $7 \%$ of subjects in the enalapril arm experienced albuminuria compared with $21 \%$ of subjects in the control arm. Enalapril had a significantly lower rate of loss of GFR compared to placebo $(p<0.05)$. 
Nielsen et al., Diabetes, 1997

Long-term effect of lisinopril and atenolol on kidney function in hypertensive NIDDM subjects with diabetic nephropathy [41]

Fogari et al., J Hum Hypertens, 1999

Long-term effects of ramipril and nitrendipine on albuminuria in hypertensive patients with type II diabetes and impaired renal function [42]
Patients with NIDDM, hypertension, and DN ( $n=43) ; 2$ groups: lisinopril, 10-20 mg daily, atenolol, 50-100 mg daily

Patients with type 2 NIDDM, hypertension, and impaired renal function ( $n=51) ; 2$ groups: ramipril, $5 \mathrm{mg}$ daily, nitrendipine $20 \mathrm{mg}$ daily
UAE was reduced to a greater extent in the lisinopril group compared to the atenolol group; reductions were $55 \%$ and $15 \%$ for the lisinopril and atenolol groups, respectively $(p=0.01)$.

Both groups experienced significant reductions in UAE in this 2-year study $(p<0.01$ and $p<0.05$ for the ramipril and nitrendipine groups, respectively); however, the ramipril group showed a significant reduction in UAE after only 3 months from $792.2 \pm 40.6$ to $609.5 \pm 47.33 \mathrm{mg} /$ 24 hours, $p<0.05)$; the nitrendipine group took 1 year to show a significant reduction in UAE from $768.4 \pm 39.2$ to $603.8 \pm 32.4 \mathrm{mg} / 24$ hours, $p<0.05$ ).

Angiotensin Receptor Blockers - Section B

\begin{tabular}{l} 
Source \\
\hline Andersen et al., Kidney Int, 2000 \\
Renoprotective effects of angiotensin II receptor \\
blockade in type 1 diabetic patients with diabetic \\
nephropathy [44]
\end{tabular}

Study Population/Design

Outcome

Patients with type 1 diabetes and persistent albuminuria ( $n=16) ; 5$ treatment phases each lasting 2 months: patients received losartan $50 \mathrm{mg}$, losartan $100 \mathrm{mg}$, enalapril $10 \mathrm{mg}$, enalapril $20 \mathrm{mg}$, and placebo in random order

Patients with type 2 diabetes and nephropathy $(\mathrm{n}=1513) ; 2$ groups: losartan (50-100 mg once daily), placebo (both groups permitted the use of conventional antihypertensive therapy)

Patients with hypertension, nephropathy, and type 2 diabetes ( $n=1715) ; 3$ groups: irbesartan, $300 \mathrm{mg}$ daily, amlodipine $10 \mathrm{mg}$ daily, placebo daily receptor antagonist irbesartan in patients with nephropathy due to type 2 diabetes [46]
Hypertensive patients with type 2 diabetes and microalbuminuria $(n=590) ; 3$ groups: irbesartan, $150 \mathrm{mg}$ daily, irbesartan, $300 \mathrm{mg}$ daily, placebo daily

The effect of irbesartan on the development diabetic nephropathy in patients with type 2 diabetes [47]

\section{Barnett AH et al., N Engl J Med, 2004}

Angiotensin-receptor blockade versus converting-enzyme inhibition in type 2 diabetes and nephropathy [48]

Viberti and Wheeldon, Circulation, 2002

Microalbuminuria reduction with valsartan in patients with type 2 diabetes mellitus: a blood pressure-independent effect [49]

\section{Lacourciere et al., Kidney Int 2000}

Long-term comparison of losartan and enalapril on kidney function in hypertensive type 2 diabetics with early nephropathy [50]

Mann et al., Ann Intern Med, 2009

Effect of telmisartan on renal outcomes: a randomized trial [51]
Patients with type 2 diabetes, hypertension, and albuminuria ( $n=250) ; 2$ groups: telmisartan, 40-80 mg daily, enalapril, 10-20 mg daily

Patients with type 2 diabetes and microalbuminuria, with or without hypertension ( $\mathrm{n}=332) ; 2$ groups: valsartan, $80 \mathrm{mg}$ daily, amlodipine $5 \mathrm{mg}$ daily

Patients with type 2 diabetes and hypertension ( $n=92) ; 2$ groups: losartan, 50 mg daily, enalapril, $5 \mathrm{mg}$ daily

Patients with cardiovascular disease or diabetes mellitus without albuminuria $(\mathrm{n}=5927) ; 2$ groups: telmisartan, $80 \mathrm{mg}$ daily, placebo daily plus standard treatment
Albuminuria and mean arterial BP decreased in both the losartan and enalapril groups compared to placebo $(p<0.05)$; GFR remained the same; no significant differences were found between the losartan $100 \mathrm{mg}$ group and the enalapril $20 \mathrm{mg}$ group.

Doubling of the $\mathrm{SrCr}$ was reduced in the losartan group compared to placebo $(p=0.006)$ during the mean 3.4-year study period; losartan reduced the progression to ESRD compared to placebo $(p=0.002)$; there was no significant difference between the two groups in decreasing death rate.

The risk of doubling of the $\mathrm{SrCr}$ was less in the irbesartan group compared to the amlodipine group $(p<0.001)$ and the placebo group $(p=0.003)$ during the mean 2.6-year study period; the risk of ESRD was less in the irbesartan group compared to the amlodipine and placebo groups ( $p=0.07$ for both); there was no difference between the three groups in regards to death rate.

After 2 years, DN developed more frequently in the placebo group compared to the irbesartan $150 \mathrm{mg}$ group $(p=0.08)$ or the irbesartan $300 \mathrm{mg}$ group $(p<0.001)$.

After 5 years, telmisartan was found to offer renal protection comparable to that of enalapril $(p>0.05)$.

UAE decreased more in the valsartan group than in the amlodipine group $(p<0.001)$ over the 24week study duration; UAE was decreased similarly in normotensive and hypertensive patients with valsartan therapy; BP remained similar between the amlodipine and valsartan groups.

After 52 weeks, patients treated with enalapril or losartan experienced significant reductions in UAE $(p<0.001)$.

After 56 months, albuminuria increased to a lesser extent in the telmisartan group compared to the placebo group $(p<0.001)$. 


\begin{tabular}{|c|c|c|}
\hline \multicolumn{3}{|c|}{ Direct Renin Inhibitors - Section C } \\
\hline Persson et al., Diabetes Care, 2009 & Patients with type 2 diabetes, hypertension, and & Aliskiren and irbesartan monotherapy reduced \\
\hline $\begin{array}{l}\text { Renal effects of aliskiren compared with and in } \\
\text { combination with irbesartan in patients with type } \\
2 \text { diabetes, hypertension, and albuminuria [54] }\end{array}$ & $\begin{array}{l}\text { albuminuria (>100 mg/day) }(\mathrm{n}=26) ; 4 \text { groups: } \\
\text { aliskiren, } 300 \mathrm{mg} \text { daily, irbesartan, } 300 \mathrm{mg} \\
\text { daily, combination aliskiren, } 300 \mathrm{mg} \text { daily, and } \\
\text { irbesartan, } 300 \mathrm{mg} \text { daily, placebo daily }\end{array}$ & $\begin{array}{l}\text { albuminuria by } 48 \% \text { and } 58 \% \text {, respectively } \\
\text { ( } p<0.001 \text { compared to placebo for both). } \\
\text { Combination therapy reduced albuminuria } \\
\text { by } 71 \% \text {, ( } p<0.001) \text { compared with placebo, } \\
\text { significantly more than with either monotherapy } \\
(p<0.001 \text { and } p=0.028 \text { ). }\end{array}$ \\
\hline Persson et al., Kidney Int, 2008 & Patients with type 2 diabetes and increased & UACR decreased by $17 \%$ from baseline after $2-4$ \\
\hline $\begin{array}{l}\text { Time course of the antiproteinuric and } \\
\text { antihypertensive effects of direct renin inhibition } \\
\text { in type } 2 \text { diabetes [55] }\end{array}$ & UACRs ( $n=15) ; 1$ group: aliskiren, 300 mg daily & $\begin{array}{l}\text { days of treatment }(p=0.04) \text { and } 44 \% \text { after } 28 \text { days } \\
\text { of treatment }(p=0.001) .24 \text {-hour BP was reduced } \\
6 \mathrm{mmHg} \text { by day } 7(p=0.037) \text { and } 8 \mathrm{mmHg} \text { by } \\
\text { day } 14 \text { ( } p=0.006) \text {. Following withdrawal, UACR } \\
\text { remained below baseline for } 12 \text { days; whereas } \\
\text { SBP remained below baseline for } 3 \text { days. }\end{array}$ \\
\hline
\end{tabular}

\section{ACE Inhibitor and ARB Combination Therapy - Section D}

\begin{tabular}{ll}
\hline \multicolumn{1}{c}{ Source } & \multicolumn{1}{c}{ Study Population/Design } \\
\hline Tutuncu et al., Acta Diabetol 2001 & $\begin{array}{l}\text { Normotensive, type } 2 \text { diabetes patients with } \\
\text { microalbuminuria }(\mathrm{n}=34) ; 3 \text { groups: (1) enalapril, } \\
\text { Efficacy of ACE inhibitors and ATII receptor }\end{array}$ \\
$\begin{array}{l}5 \text { mg daily, (2) losartan, } 50 \text { mg daily, or (3) both } \\
\text { plockers in patients with microalbuminuria: a }\end{array}$ & daily
\end{tabular}

Hebert et al., Am J Nephrol, 1999

Combination ACE inhibitor and angiotensin II receptor antagonist therapy in diabetic nephropathy [57]

\section{Agarwal, Kidney Int, 2001}

Add-on angiotensin receptor blockade with maximized ACE inhibition [58]

Rossing et al., Diabetes Care, 2002

Dual blockade of the renin-angiotensin system in diabetic nephropathy [59]

\section{Jacobsen et al., Kidney Int, 2003}

Dual blockade of the renin-angiotensin system versus maximal recommended dose of ACE inhibition in diabetic nephropathy [60]

\section{Rossing et al., Diabetes Care, 2003}

Renoprotective effects of adding angiotensin II receptor blocker to maximal recommended doses of ACE inhibitor in diabetic nephropathy [61]
Patients with DN ( $n=7)$; 1 group; week 1: patient's usual therapy of a moderate-to-high dose ACE inhibitor; week 2: usual regimen of week 1 plus oral losartan, $50 \mathrm{mg}$ or $100 \mathrm{mg}$ daily; week 3 : return to usual regimen of week 1

Patients with proteinuric moderately advanced renal failure $(n=16 ; n=12$ with $D N, n=4$ with chronic glomerulonephritis): 1 group; month 1: lisinopril, $40 \mathrm{mg}$ daily, plus other antihypertensive therapy; 2-week washout period; month 2: losartan, $50 \mathrm{mg}$ daily, in addition to month 1 treatment

Patients with type 2 diabetes and DN (albuminuria $>1 \mathrm{~g} /$ day and BP $>135 / 85$ $\mathrm{mmHg})(\mathrm{n}=18) ; 2$ groups, crossover design: group 1: candesartan $8 \mathrm{mg}$ daily plus other antihypertensive therapy ( $n=15$ diuretics, $n=11$ $C C B, n=3$ beta blocker), group 2: placebo plus other antihypertensive therapy

Patients with type 1 diabetes and DN ( $n=24)$ : 2 groups, crossover design: group 1 (8 weeks): irbesartan, $300 \mathrm{mg}$ daily, in addition to the patient's usual antihypertensive therapy including enalapril, $40 \mathrm{mg}$ daily, group 2: placebo daily plus the patient's usual antihypertensive therapy including enalapril, $40 \mathrm{mg}$ daily

Patients with type 2 diabetes, hypertension, and nephropathy $(\mathrm{n}=20)$; two groups, 8-week crossover design: candesartan, $16 \mathrm{mg}$ daily, and placebo daily in random order added to usual treatment with lisinopril/enalapril, $40 \mathrm{mg}$ daily, or captopril, $150 \mathrm{mg}$ daily
The UAER decreased by $58 \%, 59 \%$, and $60 \%$ in groups 1, 2, and 3 after 12 months of therapy ( $p=0.0001, p=0.0002, p=0.0003$, respectively). There was no significant difference between the reduction in UAER between the three groups $(p=0.346)$.

There was no difference between the combination therapy group and ACE inhibitor monotherapy group in regards to 24-hour proteinuria.

Mean 24-hour protein excretion/g creatinine and overall average BP did not change between month 1 and month 2 therapies ( $p=0.89$ and $p=0.95$, respectively).

The addition of candesartan therapy resulted in a $25 \%$ mean reduction in albuminuria $(p=0.036)$ and a $10 \mathrm{mmHg}$ reduction in 24-hour SBP $(p=0.019)$.

Albuminuria and 24-hour BP were significantly reduced with dual blockade compared to placebo $(p<0.001, p<0.005)$ during the mean 58-day study period.

Albuminuria was significantly reduced with dual blockade compared to monotherapy $(p<0.001)$. 
Fujisawa et al., Am J Hypertens, 2005

Combination of half doses of angiotensin type 1 receptor antagonist and angiotensin-converting enzyme inhibitor in diabetic nephropathy [62]

\section{Cetinkaya et al., Int J Clin Pract, 2004}

Anti-proteinuric effects of combination therapy with enalapril and losartan in patients with nephropathy due to type 2 diabetes [63]

\section{Mogensen et al., BMJ, 2000}

Randomised controlled trial of dual blockade of renin-angiotensin system in patients with hypertension, microalbuminuria, and non-insulin dependent diabetes: the candesartan and lisinopril microalbuminuria (CALM) study [64]

\section{Mann et al., Lancet, 2008}

Renal outcomes with telmisartan, ramipril, or both, in people at high vascular risk (the ONTARGET study) [65]
Patients with type 2 diabetes $(n=27)$ receiving $10 \mathrm{mg}$ imidapril or $8 \mathrm{mg}$ candesartan per day; 1 group: monotherapy with imidapril $10 \mathrm{mg}$ daily or candesartan $8 \mathrm{mg}$ daily substituted with imidapril $5 \mathrm{mg}$ and candesartan $4 \mathrm{mg}$ daily

Patients with DN ( $n=22) ; 3$ groups; 2 study periods: enalapril, $10 \mathrm{mg}$ daily, or losartan, $50 \mathrm{mg}$ daily, for 12 weeks; then 10 patients ( 5 from the enalapril and 5 from the losartan group) received $10 \mathrm{mg}$ daily of enalapril and $50 \mathrm{mg}$ daily of losartan for 12 weeks; 12 patients (6 from each group) received double doses of monotherapy ( 6 received $20 \mathrm{mg}$ daily enalapril, 6 received $100 \mathrm{mg}$ daily losartan) for 12 weeks

Patients with microalbuminuria, hypertension, and type 2 diabetes ( $n=199): 3$ groups: candesartan, $16 \mathrm{mg}$ daily, lisinopril, $20 \mathrm{mg}$ daily, combination candesartan, $16 \mathrm{mg}$ daily, and lisinopril, $20 \mathrm{mg}$ daily

Patients 55 years of age or older with atherosclerotic vascular disease or diabetes with end-organ damage $(n=25,620): 3$ groups: ramipril, $10 \mathrm{mg}$ daily, telmisartan, $80 \mathrm{mg}$ daily, or a combination of both drugs
After 3 months of combination therapy, the log-transformed urinary albumin index was significantly reduced $(p=0.003)$ from an initial urinary albumin index.

Albuminuria was decreased to a greater extent in the combination group than in either of the monotherapy groups ( $p<0.05$ for both).

The combination group decreased albuminuria and BP to a greater extent than either the lisinopril and candesartan groups alone $(p<0.001$ for all).

The increase in UAE was less with combination therapy $(p=0.001)$ or telmisartan $(p=0.004)$ than with ramipril. There was no significant difference between the telmisartan or ramipril groups in regards to the risk of developing new microalbuminuria, macroalbuminuria or both during the study ( $p=0.119)$; however, the risk was significantly lower with combination therapy than with ramipril $(p=0.003)$. Of those patients with microalbuminuria at baseline, there was no difference in progression to macroalbuminuria between telmisartan and ramipril $(p=0.114)$; however, fewer patients progressed to macroalbuminuria in the combination group compared to the ramipril group $(p=0.019)$.

\begin{tabular}{|c|c|c|}
\hline \multicolumn{3}{|c|}{ Direct Renin Inhibitor Combinations - Section E } \\
\hline Source & Study Population/Design & Outcome \\
\hline $\begin{array}{l}\text { Persson et al., Clin J Am Soc Nephrol, } 2011 \\
\text { Aliskiren in combination with losartan reduces } \\
\text { albuminuria independent of baseline blood } \\
\text { pressure in patients with type } 2 \text { diabetes and } \\
\text { nephropathy [67] }\end{array}$ & $\begin{array}{l}\text { Patients with hypertension, type } 2 \text { diabetes } \\
\text { and nephropathy ( } \mathrm{n}=599): 2 \text { groups: aliskiren } \\
\text { ( } 150 \mathrm{mg} \text { force-titrated to } 300 \text { mg daily after } \\
3 \text { months) or placebo added to losartan ( } 100 \\
\text { mg) daily and optimal antihypertensive therapy. } \\
\text { Patients were divided into three groups based } \\
\text { on BP level at the time of randomization (Group A } \\
\text { prespecified BP target, }<130 / 80 \mathrm{mmHg} \text { [ } \mathrm{n}=159] ; \\
\text { Group B intermediate BP control, }<140 / 90 \mathrm{mmHg} \\
\text { but } \geq 130 / 80 \mathrm{mmHg}[\mathrm{n}=189] ; \text { and } \mathrm{Group} \mathrm{C} \\
\text { insufficient BP control, } \geq 140 / 90 \mathrm{mmHg}[\mathrm{n}=251] \text { ) }\end{array}$ & $\begin{array}{l}\text { The combination of losartan and aliskiren resulted } \\
\text { in a } 20 \% \text { greater decrease in the UACR compared } \\
\text { to the losartan and placebo group. This decrease } \\
\text { was consistent across baseline BP groups but } \\
\text { statistically significant only in hypertensive subjects } \\
\text { (group C, } p=0.044 \text { ). }\end{array}$ \\
\hline $\begin{array}{l}\text { ALTITUDE Investigators, N Engl J Med, } 2012 \\
\text { Cardiorenal end points in a trial of aliskiren } \\
\text { for type } 2 \text { diabetes [68] }\end{array}$ & $\begin{array}{l}\text { Patients } 35 \text { years of age and older with type } 2 \\
\text { diabetes and evidence of microalbuminuria, } \\
\text { macroalbuminuria, or cardiovascular disease } \\
\text { (n=8561): } 2 \text { groups: aliskiren (initial dose } 150 \mathrm{mg} \\
\text { once daily increased to } 300 \mathrm{mg} \text { once daily } 4 \text { weeks } \\
\text { after randomization) or placebo, in addition to } \\
\text { standard treatment }\end{array}$ & $\begin{array}{l}\text { The reduction in UACR between baseline and } 6 \\
\text { months was significantly different in the aliskiren } \\
\text { group }(16 \%) \text { compared to the placebo group }(5 \%) \\
(p<0.001) .\end{array}$ \\
\hline
\end{tabular}

doi: 10.7573/dic.212249.t001 
$(\mathrm{n}=1150,13.5 \%$; hazard ratio (HR): $1.0,95 \% \mathrm{CI}: 0.92-1.09)$, and increased with combination therapy $(n=1233,14.5 \%$; HR: 1.09, 95\% CI: 1.01-1.18; $p=0.037$ ). The secondary renal endpoint of any dialysis or doubling of serum creatinine was similar with telmisartan $(n=189,2.21 \%)$ and ramipril $(n=174,2.03 \%$; HR: 1.09, 95\% CI: 0.89-1.34) and more frequent with combination therapy $(\mathrm{n}=212,2.49 \%$; HR: $1.24,95 \% \mathrm{CI}: 1.01-1.51$; $p=0.038$ ). Participants of the ONTARGET study were recruited from a population with reduced autoregulatory capacity by the kidneys thus placing them at greater risk for adverse renal events. However, patients at high risk for acute kidney injury and hyperkalemia represent a significant component of clinical practice that would be considered for combination therapy, increasing the generalizability of the study.

A further analysis was conducted to test the effect of dual blockade of the RAS on strokes in subjects with diabetes mellitus (either a history of diabetes or a fasting plasma glucose $>7$ $\mathrm{mmol} / \mathrm{L}$ ) given that dual blockade is often used to reduce albuminuria [66]. A subgroup analysis was conducted to examine the effects of addition of ramipril to telmisartan in subjects with diabetes $(n=9628$, mean age 66 years, baseline blood pressure $144 / 82 \mathrm{mmHg}$, body mass index $29 \mathrm{~kg} / \mathrm{m}^{2}$ ) divided into those with $(n=3163)$ and without $(n=6465)$ nephropathy. The authors compared participants on monotherapy with either ramipril or telmisartan with those on dual therapy [66].

There was a greater reduction in SBP with dual versus monotherapy $(-7.1 v s-5.3 \mathrm{mmHg} ; p<0.0001)$, but a similar number of strokes between groups (1.19 vs 1.22 per 100 patient years; HR: 0.99, 95\% CI: 0.82-1.20). Stroke rate was higher in participants with DN than those without (1.5 vs 1.0 per 100 patient years), but the effects of dual therapy compared with monotherapy were not different in participants with $\mathrm{DN}$ and those without $\mathrm{DN}$ (1.59 vs 1.55 and 1.01 vs 1.08 per 100 patient years; $p$ value for interaction=0.60). Other cardiovascular and kidney outcomes (dialysis or doubling of serum creatinine) did not differ between combination therapy and monotherapy in subgroups [66]. The incidence of dialysis-dependent acute kidney injury was higher in subjects receiving combination therapy than in the monotherapy group, 0.14 compared with 0.08 cases per 100 patient years (HR: 1.55, 95\% CI: 0.84-2.85), and hyperkalemia was more frequent, 1.82 compared with 1.07 cases per 100 patient years (HR: 1.71, 95\% CI: 1.44-2.02). Both adverse outcomes were more frequent in those with renal disease; however, the excess due to dual therapy was similar in those with and without renal disease [66].

Symptomatic hypotension (191 cases) occurred more frequently with combination therapy than with monotherapy (HR: 2.30, 95\% CI: 1.74-3.04); the risk for hypotension with combination therapy was 1.51-fold higher than with monotherapy in those with a significant renal disease but 2.87-fold higher in those without ( $p$ value for interaction=0.05). Syncope was rare (five vs four cases) [66].

The authors concluded that due to the lack of clinical benefit, and a greater incidence of adverse renal events, dual blockade of the RAS, combining an ACE inhibitor, an ARB or aliskiren, is not recommended in patients with type 2 diabetes with or without nephropathy.

\section{Direct renin inhibitor combinations}

The first large clinical trial in patients with type 2 diabetes was the Aliskiren in the Evaluation of Proteinuria in Diabetes (AVOID) study (Table 1, Section E) [67,68], which randomized 599 hypertensive patients with type 2 diabetes and nephropathy to 6 months of aliskiren $(150 \mathrm{mg}$ force-titrated to $300 \mathrm{mg}$ daily after 3 months) or placebo added to losartan (100 mg) daily and optimal antihypertensive therapy. Patients were divided into three groups based on blood pressure level at the time of randomization (Group A: prespecified blood pressure target, $<130 / 80 \mathrm{mmHg}(\mathrm{n}=159)$; Group B: intermediate blood pressure control, $<140 / 90 \mathrm{mmHg}$ but $\geq 130 / 80 \mathrm{mmHg}(\mathrm{n}=189)$; and Group C: insufficient blood pressure control, $\geq 140 / 90 \mathrm{mmHg}$ $(\mathrm{n}=251))$. The combination of losartan and aliskiren resulted in a 20\%-greater decrease in the urinary albumin/creatinine ratio (UACR) compared to the losartan and placebo group. This decrease was consistent across baseline blood pressure groups although it was statistically significant only in hypertensive subjects (Group C, $p=0.044$ ) [67].

There were significantly more reported symptoms of hypotension among the aliskiren-treated patients in Group A compared with placebo patients $(p=0.005)$, but no patient in Group A discontinued the study as a result of hypotension. The results of this study prompted further investigation into the benefit of combining aliskiren with an ACE-inhibitor or an ARB.

The Aliskiren Trial in Type 2 Diabetes Using Cardiovascular and Renal Disease Endpoints (ALTITUDE) study [68] was conducted to determine whether the DRI aliskiren would reduce cardiovascular and renal events in patients with type 2 diabetes and CKD, cardiovascular disease, or both. This multicenter double-blind, placebo-controlled trial randomly assigned 8561 patients to aliskiren, $300 \mathrm{mg}$ daily, or placebo in addition to an ACE inhibitor or ARB. The primary cardiorenal endpoint was the time to cardiovascular death or a first occurrence of a cardiovascular event (e.g., cardiac arrest with resuscitation; nonfatal myocardial infarction; nonfatal stroke; ESRD; death attributable to kidney failure; or doubling of the baseline serum creatinine level). While the mean reduction in the UACR was greater in the aliskiren group (between-group difference $14 \%$, 95\% CI: 11-17), the proportion of patients with hyperkalemia (serum potassium level $\geq 6 \mathrm{mmol} / \mathrm{L}$ ) was significantly higher in the aliskiren group compared to the placebo group $(11.2 \%$ vs $7.2 \% ; p<0.001)$, as was the proportion with reported hypotension $(12.1 \%$ vs $8.3 \%$; $p<0.001)$. After a median follow-up of 33 months, the primary endpoint had occurred in 783 patients (18.3\%) assigned to aliskiren compared with $732(17.1 \%)$ assigned to placebo (HR: 1.08, 95\% CI: 0.98-1.20; $p=0.12$ ). The Data Monitoring Committee recommended early termination of the trial because the excess risk of adverse events did not offset the benefits in the reduction of cardiovascular and renal events.

Harel and colleagues [69] conducted a systematic review which included 10 studies that compared combined treatment, using aliskiren with an ACE inhibitor or an ARB, with monotherapy using these agents. The risk of hyperkalemia was significantly higher among subjects given aliskiren in combination with an ACE inhibitor or ARB than among those given ACE inhibitor 
or ARB monotherapy (relative risk: 1.58, 95\% CI: 1.24-2.02; risk difference $0.02,95 \%$ CI: $0.01-0.04$; number needed to harm 43, 95\% CI: $\left.28-90 ; I^{2}=0\right)$. However, the risk of acute kidney injury did not differ significantly between participants given aliskiren in combination with an ACE inhibitor or an ARB than among those given ACE inhibitor or ARB monotherapy (relative risk $1.14,95 \%$ CI: $0.68-1.89$; $\mathrm{I}^{2}=30 \%$ ) or aliskiren monotherapy (relative risk $0.80,95 \%$ CI: $0.31-2.04 ; \mathrm{I}^{2}=0 \%$ ).

Adverse events were infrequent, which meant that many of the studies pooled in this meta-analysis did not have an adequate sample size to assess safety outcomes. Harel and colleagues indicated that the populations studied varied widely and included patients with hypertension, diabetes, congestive heart failure, and recent acute coronary syndrome, who may possess differential risks for hyperkalemia and acute kidney injury. However, the original study data on these subjects were not available to Harel and colleagues, which limited their ability to account for the differences in the risk for hyperkalemia and acute kidney injury between the different groups. While this heterogeneity among the studies limited the ability to identify differences in risk of adverse events between the groups, it is our opinion that it increases the generalizability of this review since patients at high risk for hyperkalemia and acute kidney injury represent a significant component of clinical practice that would be considered for combination therapy.

\section{Conclusions}

Complications of diabetes, particularly renal and cardiovascular disease, substantially increase the risk of subsequent severe illness and death. The use of ACE inhibitors and ARBs has been shown to reduce the incidence of major cardiovascular events and delay the progression of DN [10,32-51]. DRIs have also been found to delay DN [52-55]. Theoretically, further reduction of proteinuria by combined ACE-inhibitor and ARB or DRI therapy might have been expected to protect the kidney from chronic kidney failure compared with monotherapy with these agents alone. However, the ONTARGET and ALTITUDE trials have shown that combination therapy with RAS blockade in patients with type 2 diabetes who are at high risk for cardiovascular and renal events is associated with hyperkalemia, hypotension, and/ or acute kidney injury/failure and should be avoided [65-69]. Due to the lack of clinical benefit, and a greater incidence of adverse renal events, dual blockade of the RAS, combining an ACE inhibitor, an ARB or aliskiren, is not recommended in patients with diabetes. Diuretics, CCBs, or beta-blockers can be used if there is a contraindication to the use of an ACE inhibitor or an $\mathrm{ARB}$, or in combination with an ACE inhibitor or ARB if treatment goals are not yet obtained.

\section{Contributions}

Eva Vivian conceived the idea and supervised the preparation of the manuscript, background literature search, and served as lead author of the paper. Chelsea Mannebach created the Summary of Clinical Trials Table 1. Both authors provided: 1) substantial contributions to conception and design, and interpretation of data; 2) drafting of the article and critical revision for important intellectual content; and 3) final approval of the version to be published.

\section{References}

1. Gross JL, de Azevedo MJ, Silveiro SP, Canani LH, Caramori ML, Zelmanovitz T. Diabetic nephropathy: diagnosis, prevention, and treatment. Diabetes Care 2005;28:164-76.

2. Collins AJ, Foley RN, Chavers B et al. United States Renal Data System 2012 Annual Data Report. Am J Kidney Dis 2012;59(1 Suppl 1):A7,e1-420.

3. Garg JP, Bakris GL. Microalbuminuria: marker of vascular dysfunction, risk factor for cardiovascular disease. Vasc Med 2002;7:35-43.

4. Klausen K, Borch-Johnsen K, Feldt-Rasmussen B et al. Very low levels of microalbuminuria are associated with increased risk of coronary heart disease and death independently of renal function, hypertension, and diabetes. Circulation 2004;110:32-5.

5. Klag MJ, Whelton PK, Randall BL et al. Blood pressure and end-stage renal disease in men. N Engl J Med 1996;334: $13-8$.

6. U.S. Department of Health and Human Services. Seventh Report of the Joint National Committee on Prevention, Detection, Evaluation, and Treatment of High Blood Pressure. 2003. Available at: http://www.nhlbi.nih.gov/guidelines/hypertension/jncintro.htm. [Last accessed: 6 April 2012].

7. Wang SL, Head J, Stevens L, Fuller JH. Excess mortality and its relation to hypertension and proteinuria in diabetic patients. The World Health Organization multinational study of vascular disease in diabetes. Diabetes Care 1996;19: 305-12.

8. Larkins RG, Dunlop ME. The link between hyperglycaemia and diabetic nephropathy. Diabetologia 1992;35:499-504.

9. Centers for Disease Control and Prevention. National diabetes fact sheet: national estimates and general information on diabetes and prediabetes in the United States, 2011. Atlanta, GA: U.S. Department of Health and Human Services, Centers for Disease Control and Prevention, 2011.

10. American Diabetes Association. Standards of medical care in diabetes - 2013. Diabetes Care 2013;36(Suppl 1):S11-66.

11. ONTARGET Investigators: Yusuf S, Teo KK, Pogue J et al. Telmisartan, ramipril, or both in patients at high risk for vascular events. N Engl J Med 2008;358:1547-59.

12. Chowdhury TA, Kumar S, Barnett AH, Bain SC. Nephropathy in type 1 diabetes: the role of genetic factors. Diabet Med 1995;12:1059-67.

13. Parving HH, Jacobsen P, Tarnow L et al. Effect of deletion polymorphism of angiotensin converting enzyme gene on progression of diabetic nephropathy during inhibition of angiotensin converting enzyme: observational follow up study. BMJ 1996;313:591-4.

14. Cowie CC, Port FK, Wolfe RA et al. Disparities in incidence of end-stage renal disease according to race and type of diabetes. N Engl J Med 1989;321:1074-9. 
15. Sawicki PT, Didjurgeit U, Muhlhauser I, Bender R, Heinemann L, Berger M. Smoking is associated with progression of diabetic nephropathy. Diabetes Care 1994;17:126-31.

16. Keane WF. Lipids and the kidney. Kidney Int 1994;46: 910-20.

17. Kramer HJ, Nguyen QD, Curhan G, Hsu CY. Renal insufficiency in the absence of albuminuria and retinopathy among adults with type 2 diabetes mellitus. JAMA 2003;289: 3273-7.

18. Tsalamandris C, Allen TJ, Gilbert RE et al. Progressive decline in renal function in diabetic patients with and without albuminuria. Diabetes 1994;43:649-55.

19. National Kidney Foundation. KDOQI Clinical Practice Guideline for Diabetes and CKD: 2012 update. Am J Kidney Dis 2012;60:850-86.

20. National Kidney Foundation. KDOQI Clinical practice guidelines and clinical practice recommendations for diabetes and chronic kidney disease. Guideline 1: Screening and diagnosis of diabetic kidney disease. Am J Kidney Dis 2007;49(Suppl 2):S42-61.

21. Handelsman Y, Mechanick JI, Blonde L et al. American Association of Clinical Endocrinologists Medical Guidelines for Clinical Practice for developing a diabetes mellitus comprehensive care plan. Endocr Pract 2011;17(Suppl 2): $1-53$.

22. Atkins RC, Zimmet P; 2010 International Society of Nephrology/International Federation of Kidney Foundations World Kidney Day Steering Committee (RA); International Diabetes Federation (PZ). Diabetic kidney disease: act now or pay later. J Bras Nefrol 2010;32:7-10.

23. Robertson L, Waugh N, Robertson A. Protein restriction for diabetic renal disease. Cochrane Database Syst Rev 2007;(4):CD002181.

24. Diabetes Control and Complications Trial Research Group. The effect of intensive treatment of diabetes on the development and progression of long-term complications in insulin-dependent diabetes mellitus. N Engl J Med 1993;329: 977-86.

25. UK Prospective Diabetes Study Group. Intensive bloodglucose control with sulphonylureas or insulin compared with conventional treatment and risk of complications in patients with type 2 diabetes (UKPDS 33). Lancet 1998;352: $837-53$.

26. Arauz-Pacheco C, Parrott MA, Raskin P; American Diabetes Association. Hypertension management in adults with diabetes. Diabetes Care 2004;27(Suppl 1):S65-7.

27. Haffner SM; American Diabetes Association. Dyslipidemia management in adults with diabetes. Diabetes Care 2004;27(Suppl 1):S68-71.

28. Moorhead JF. Lipids and progressive kidney disease. Kidney Int Suppl 1991;31:S35-40.

29. UK Prospective Diabetes Study Group. Tight blood pressure control and risk of macrovascular and microvascular complications in type 2 diabetes: UKPDS 38. BMJ 1998;317: 703-13.

30. Remuzzi G, Macia M, Ruggenenti P. Prevention and treatment of diabetic renal disease in type 2 diabetes: the
BENEDICT study. J Am Soc Nephrol 2006; 17(Suppl.2):S90-7

31. ROADMAP Trial Investigators; Haller $\mathrm{H}$, Ito S, Izzo JL Jr et al. Olmesartan for the delay or prevention of microalbuminuria in type 2 diabetes. N Engl J Med 2011;364: 907-17.

32. Mathiesen ER, Hommel E, Giese J, Parving HH. Efficacy of captopril in postponing nephropathy in normotensive insulin dependent diabetic patients with microalbuminuria. BMJ 1991;303:81-7.

33. Ahmad J, Siddiqui MA, Ahmad H. Effective postponement of diabetic nephropathy with enalapril in normotensive type 2 diabetic patients with microalbuminuria. Diabetes Care 1997;20:1576-81.

34. Lewis EJ, Hunsicker LG, Bain RP, Rohde RD. The effect of angiotensin-converting-enzyme inhibition on diabetic nephropathy. N Engl J Med 1993;329:1456-62.

35. Ravid M, Savin H, Jutrin I, Bental T, Katz B, Lishner M. Long-term stabilizing effect of angiotensin-converting enzyme inhibition on plasma creatinine and on proteinuria in normotensive type II diabetic patients. Ann Intern Med 1993;118:577-81.

36. Ravid M, Brosh D, Levi Z, Bar-Dayan Y, Ravid D, Rachmani R. Use of enalapril to attenuate decline in renal function in normotensive, normoalbuminuric patients with type 2 diabetes mellitus: A randomized, controlled trial. Ann Intern Med 1998;128:982-8.

37. The EUCLID Study Group. Randomized placebo-controlled trial of lisinopril in normotensive patients with insulin-dependent diabetes and normoalbuminuria or microalbuminuria. Lancet 1997;349:1787-92.

38. Viberti G, Mogensen CE, Groop LC, Pauls JF. Effect of captopril on progression to clinical proteinuria in patients with insulin-dependent diabetes mellitus and microalbuminuria. European Microalbuminuria Captopril Study Group. JAMA 1994;271:275-9.

39. Sano T, Kawamura T, Matsumae $H$ et al. Effects of longterm enalapril treatment on persistent microalbuminuria in well-controlled hypertensive and normotensive NIDDM patients. Diabetes Care 1994;17:420-4.

40. Lebovitz HE, Wiegmann TB, Cnaan A et al. Renal protective effects of enalapril in hypertensive NIDDM: role of baseline albuminuria. Kidney Int Suppl 1994;45: S150-5.

41. Nielsen FS, Rossing P, Gall MA, Skott P, Smidt UM, Parving $\mathrm{HH}$. Long-term effect of lisinopril and atenolol on kidney function in hypertensive NIDDM subjects with diabetic nephropathy. Diabetes 1997;46:1182-8.

42. Fogari R, Zoppi A, Corradi L et al. Long-term effects of ramipril and nitrendipine on albuminuria in hypertensive patients with type II diabetes and impaired renal function. J Hum Hypertens 1999;13:47-53.

43. Vivian EM, Goebig ML. Slowing the progression of renal disease in diabetic patients. Ann Pharmacother 2001;35: 452-63.

44. Andersen S, Tarnow L, Rossing P, Hansen BV, Parving HH. Renoprotective effects of angiotensin II receptor blockade in 
type 1 diabetic patients with diabetic nephropathy. Kidney Int 2000;57:601-6.

45. Brenner BM, Cooper ME, de Zeeuw D et al. Effects of losartan on renal and cardiovascular outcomes in patients with type 2 diabetes and nephropathy. $\mathrm{N}$ Engl J Med 2001;345:861-9.

46. Lewis EJ, Hunsicker LG, Clarke WR et al. Renoprotective effect of the angiotensin-receptor antagonist irbesartan in patients with nephropathy due to type 2 diabetes. $\mathrm{N} \mathrm{Engl} \mathrm{J}$ Med 2001;345:851-60.

47. Parving HH, Lehnert $\mathrm{H}$, Brochner-Mortensen J et al. The effect of irbesartan on the development of diabetic nephropathy in patients with type 2 diabetes. $\mathrm{N}$ Engl J Med 2001;345:870-8.

48. Barnett AH, Bain SC, Bouter P et al. Angiotensin-receptor blockade versus converting-enzyme inhibition in type 2 diabetes and nephropathy. N Engl J Med 2004;351:1952-61.

49. Viberti G, Wheeldon NM; MicroAlbuminuria Reduction With VALsartan (MARVAL) Study Investigators. Microalbuminuria reduction with valsartan in patients with type 2 diabetes mellitus: a blood pressure-independent effect. Circulation 2002;106:672-8.

50. Lacourciere $Y$, Belanger A, Godin C et al. Long-term comparison of losartan and enalapril on kidney function in hypertensive type 2 diabetics with early nephropathy. Kidney Int 2000;58:762-9.

51. Mann JF, Schmieder RE, Dyal L et al. Effect of telmisartan on renal outcomes: a randomized trial. Ann Intern Med 2009;151:1-10.

52. Wood JM, Maibaum J, Rahuel J et al. Structure-based design of aliskiren, a novel orally effective renin inhibitor. Biochem Biophys Res Commun 2003;308:698-705.

53. Katzung BG. Basic and Clinical Pharmacology. $11^{\text {th }}$ ed. San Francisco, CA: McGrawHill; 2009.

54. Persson F, Rossing P, Reinhard $\mathrm{H}$ et al. Renal effects of aliskiren compared with and in combination with irbesartan in patients with type 2 diabetes, hypertension, and albuminuria. Diabetes Care 2009;32:1873-9.

55. Persson F, Rossing P, Schjoedt KJ et al. Time course of the antiproteinuric and antihypertensive effects of direct renin inhibition in type 2 diabetes. Kidney Int 2008;73:1419-25.

56. Tutuncu NB, Gurlek A, Gedik O. Efficacy of ACE inhibitors and ATII receptor blockers in patients with microalbuminuria: a prospective study. Acta Diabetol 2001;38:157-61.

57. Hebert LA, Falkenhain ME, Nahman NS, Cosio FG, O'Dorisio TM. Combination ACE inhibitor and angiotensin II receptor antagonist therapy in diabetic nephropathy. Am J Nephrol 1999;19:1-6.
58. Agarwal R. Add-on angiotensin receptor blockade with maximized ACE inhibition. Kidney Int 2001;59:2282-9.

59. Rossing K, Christensen PK, Jensen BR, Parving HH. Dual blockade of the renin-angiotensin system in diabetic nephropathy: a randomized double-blind crossover study. Diabetes Care 2002;25:95-100.

60. Jacobsen P, Andersen S, Rossing K, Jensen BJ, Parving HH. Dual blockade of the renin-angiotensin system versus maximal recommended dose of ACE inhibition in diabetic nephropathy. Kidney Int 2003;63:1874-80.

61. Rossing K, Jacobsen P, Pietraszek L, Parving HH. Renoprotective effects of adding angiotensin II receptor blocker to maximal recommended doses of ACE inhibitor in diabetic nephropathy: a randomized double-blind crossover trial. Diabetes Care 2003;26:2268-74.

62. Fujisawa T, Ikegami H, Ono $\mathrm{M}$ et al. Combination of half doses of angiotensin type 1 receptor antagonist and angiotensin-converting enzyme inhibitor in diabetic nephropathy. Am J Hypertens 2005;18:13-7.

63. Cetinkaya R, Odabas AR, Selcuk Y. Anti-proteinuric effects of combination therapy with enalapril and losartan in patients with nephropathy due to type 2 diabetes. Int J Clin Pract 2004;58:432-5.

64. Mogensen CE, Neldam S, Tikkanen I et al. Randomised controlled trial of dual blockade of renin-angiotensin system in patients with hypertension, microalbuminuria, and noninsulin dependent diabetes: the candesartan and lisinopril microalbuminuria (CALM) study. BMJ 2000;321:1440-4.

65. Mann JF, Schmieder RE, McQueen M et al. Renal outcomes with telmisartan, ramipril, or both, in people at high vascular risk (the ONTARGET study): a multicentre, randomised, double-blind, controlled trial. Lancet 2008;372:547-53.

66. Mann JF, Anderson C, Gao P et al. Dual Inhibition of the renin-angiotensin system in high-risk diabetes and risk for stroke and other outcomes: results of the ONTARGET trial. J Hypertens 2013;31:414-21

67. Persson F, Lewis JB, Lewis EJ, Rossing P, Hollenberg NK, Parving HH. Aliskiren in combination with losartan reduces albuminuria independent of baseline blood pressure in patients with type 2 diabetes and nephropathy. Clin J Am Soc Nephrol 2011;6:1025-31.

68. ALTITUDE Investigators: Parving HH, Brenner BM, McMurray JJ et al. Cardiorenal end points in a trial of aliskiren for type 2 diabetes. N Engl J Med 2012;367:2204-13.

69. Harel Z, Gilbert C, Wald R et al. The effect of combination treatment with aliskiren and blockers of the renin-angiotensin system on hyperkalaemia and acute kidney injury: systematic review and meta-analysis BMJ 2012;344:e42. 